\title{
CD4 T cell activation by B cells in human Leishmania (Viannia) infection
}

Daniel Rodriguez-Pinto ${ }^{1,3^{*}}$, Nancy Gore Saravia ${ }^{1}$ and Diane McMahon-Pratt ${ }^{2}$

\begin{abstract}
Background: An effective adaptive immune response requires activation of specific CD4 T cells. The capacity of B cells to activate CD4 T cells in human cutaneous leishmaniasis caused by Leishmania (Viannia) has not been evaluated.
\end{abstract}

Methods: CD4 T cell activation by B cells of cutaneous leishmaniasis patients was evaluated by culture of PBMCs or purified B cells and CD4 T cells with Leishmania panamensis antigens. CD4 T cell and B cell activation markers were evaluated by flow cytometry and 13 cytokines were measured in supernatants with a bead-based capture assay. The effect of Leishmania antigens on BCR-mediated endocytosis of ovalbumin was evaluated in the Ramos human $\mathrm{B}$ cell line by targeting the antigen with anti-IgM-biotin and anti-biotin-ovalbumin-FITC.

Results: Culture of PBMCs from cutaneous leishmaniasis patients with Leishmania antigens resulted in upregulation of the activation markers CD25 and CD69 as well as increased frequency of CD25 ${ }^{\text {hi }}$ CD127 $7^{-}$cells among CD4 T cells. Concomitantly, B cells upregulated the costimulatory molecule CD86. These changes were not observed in PBMCs from healthy subjects, indicating participation of Leishmania-specific lymphocytes expanded in vivo. Purified B cells from these patients, when interacting with purified CD4 T cells and Leishmania antigens, were capable of inducing significant increases in CD25 and CD69 expression and CD25 ${ }^{\text {hi }}$ CD127- frequency in CD4 T cells. These changes were associated with upregulation of CD86 in B cells. Comparison of changes in CD4 T cell activation parameters between PBMC and B cell/CD4 T cell cultures showed no statistically significant differences; further, significant secretion of IFN- $\gamma$, TNF- $\alpha$, IL-6 and IL-13 was induced in both types of cultures. Additionally, culture with Leishmania antigens enhanced BCR-mediated endocytosis of ovalbumin in Ramos human B cells.

Conclusions: The capacity of B cells specific for Leishmania antigens in peripheral blood of cutaneous leishmaniasis patients to activate CD4 T cells and induce cytokine secretion is similar to that of all cell populations present in PBMCs. This capacity implicates B cells as a plausible target for modulation of the immune response to Leishmania infection as a therapeutic strategy.

Keywords: B cells, Cutaneous leishmaniasis, Leishmania (Viannia)

\section{Background}

Leishmaniasis is a parasitic disease endemic in 88 countries that affects an estimated 12 million people in the rural areas of the tropical and subtropical regions of the world. In South America, Leishmania species of the Viannia subgenus cause cutaneous and muco-cutaneous disease that can become chronic and cause severe disfigurement. In

\footnotetext{
*Correspondence: derodriguez@udla.edu.ec

'Centro Internacional de Entrenamiento e Investigaciones Médicas (CIDEIM), Cali, Colombia

${ }^{3}$ Current Address: Facultad de Medicina, Facultad de Ciencias de la Salud, Universidad de las Américas, Quito, Ecuador

Full list of author information is available at the end of the article
}

spite of the advances in knowledge of parasite biology and the host immune response, effective and safe treatment remains a challenge and there is yet no approved vaccine $[1,2]$. These needs may be addressed by manipulating the host immune response to obtain parasite elimination without tissue damage.

Professional antigen presenting cells (APCs) initiate the adaptive immune response by activating $\mathrm{CD} 4 \mathrm{~T}$ cells. Activation of APCs, in the form of MHCII molecule upregulation and costimulatory molecule expression, is essential for induction of immunity, and the cytokines secreted during antigen presentation shape the ensuing 
response. In the murine model of cutaneous leishmaniasis (CL) caused by L. major, IL-12 secretion by APCs is crucial for generation of IFN- $\gamma$-secreting Th1 cells, macrophage activation and parasite elimination [3]. Failure to generate a Th1 response leads to chronic disease. In the human disease caused by L. (Viannia), cells from patients with chronic disease secrete large amounts of IFN- $\gamma$ and TNF- $\alpha$ but also Th2 and regulatory cytokines such as IL-13 and IL-10, resulting in an unbalanced immune response, excessive inflammation, tissue damage, and parasite survival [4-8]. A similar picture was observed in a murine model of chronic $L$. $(V$.) panamensis infection where IL-13 was shown to be crucial for development of pathology [4]. Since CD4 T cell activation by APCs leads to this harmful response, modulation of this event could promote healing or prevent disease.

Three types of APCs are recognized: dendritic cells (DCs), macrophages and B cells. As the natural host of Leishmania, macrophages would be the ideal candidates for initiating the adaptive immune response in CL. However, it is well documented that infection of macrophages with Leishmania does not induce MHCII molecule upregulation, costimulatory molecule expression or IL-12 secretion, but rather inhibits these processes, shutting down antigen presentation by macrophages. These effects have been shown in a range of Leishmania species in both animal models and human cells [9-12]. On the other hand, DC function has been more difficult to determine, as both activation and inhibition of APC function have been found. In the murine L. major model it is well recognized that DCs initiate the immune response and secrete IL-12 in the resistant phenotype [13]. However, studies with other Leishmania species have shown that infection with parasites does not lead to DC activation [14-18]. Notably, L. (V.) braziliensis infection of DCs inhibits cell activation and antigen presentation while uninfected neighboring DCs are able to upregulate MHCII and costimulatory molecules and induce $\mathrm{T}$ cell activation [18]. Thus, it seems that induction of immunity by DCs in CL depends on their avoidance of infection. In summary, both macrophage and DC APC function can be inhibited by L. (Viannia). Therefore, the participation of B cells in CD4 $\mathrm{T}$ cell activation in CL caused by species of this subgenus may be crucial.

The role of B cells in human CL caused by L. (Viannia) has not been defined. Histological studies in Colombian patients infected with $L$. (Viannia) have revealed prominent $B$ cell infiltration of skin lesions and leishmanin skin test reaction sites $[19,20]$, and a study from Brazil showed a significant increase in B cell frequency in lymph node aspirates of patients that presented lymphadenopathies associated with the late stage of lesion development [21]. These findings suggest that B cells may play an important role in the immune response to L. (Viannia). In mice, lesion development caused by L. panamensis was found to be delayed in the absence of B cells, although final lesion size and parasite load were not affected [4]. B cells have been shown in murine models of leishmaniasis to contribute to immunologic regulation through production of cytokines and immunoglobulins and as a result of antigen presentation [22-29]. However, variation occurs that may depend upon the species, specific Leishmania strain and mouse genetics [27,29].

The contribution of B cells in CD4 T cell activation in human CL or its pathogenesis is yet unexplored. B cells specific for a particular antigen have an exquisite capacity to concentrate and direct the antigen to the appropriate processing compartments. Furthermore, BCR signaling induces optimal APC activation, making B cells competent APCs capable of activating naïve CD4 T cells. Hence, the participation of B cells as APCs has been shown to be essential in many different contexts [30-35]. Furthermore, their capacity to secrete several cytokines capable of inducing Th1, Th2 and regulatory responses has been well documented [36]. For these reasons, and in order to identify immunomodulatory intervention strategies we have examined the capacity of B cells to activate CD4 T cells in CL.

In the present study, CD4 T cell activation by B cells was assessed in cells from patients with CL caused by L. (Viannia) species. We found that B cells upregulated the costimulatory molecule CD86 in PBMC cultures stimulated with $L$. panamensis and were able to activate CD4 $\mathrm{T}$ cells and induce cytokine secretion in the absence of other recognized APCs. Furthermore, we show that exposure to L. panamensis antigen enhances BCR-mediated endocytosis by the Ramos human B cell line. Taken together these results indicate a role for B cells in the modulating the immune response to L. panamensis.

\section{Methods \\ Study design}

We evaluated the response of cells from CL patients from the southwestern region of Colombia where most cases are caused by L. panamensis or L. braziliensis. We have previously shown that there is a strong recall response to L. panamensis antigens in patients from this region regardless of the infecting species [37-39]. Thus, we stimulated cells with promastigote $L$. panamensis antigen (pLAg) obtained from L. panamensis strain MHOM/ COL/81/L13. First, we compared CD4 T cell and APC activation in CL patients and healthy subjects by culturing PBMCs with pLAg and measuring CD4 T cell, B cell and DC activation markers. We then determined the competence of B cells for CD4 T cell activation by culturing them with CD4 T cells and pLAg and evaluating activation of both cell types. We evaluated the cytokine secretion profile of PBMC and B cell/CD4 T cell cultures 
to establish whether the cytokine profile induced by $\mathrm{B}$ cell-CD4 T cell interaction is similar to that induced when all PBMCs participate. Finally, we examined the effects of exposure to pLAg on a human B cell line in relation with induction of activation markers and BCR-mediated endocytosis.

\section{Human subjects and cells}

Peripheral blood samples (60 to $100 \mathrm{~mL}$ ) were obtained from CL patients from the southwestern region of Colombia (Departments of Valle del Cauca and Nariño). Participants included 8 males and 2 females of 20 to 65 years of age (median $=27$ ), who had typical cutaneous lesions, were parasitologically diagnosed by smear, culture or biopsy, and had not received anti-leishmanial treatment before enrollment. Blood samples from four healthy subjects from non-endemic areas were obtained as controls. All subjects had negative serology for HIV and HTLV-1. All participants provided written informed consent. The study protocol, consent forms and all procedures were approved by the CIDEIM Institutional Review Board for the ethical conduct of research involving human subjects.

PBMCs were isolated by centrifugation over Histopaque1077 (Sigma-Aldrich, St. Louis, MO). B cells and CD4 T cells were isolated by MACS using the B cell isolation and $\mathrm{CD}^{+} \mathrm{T}$ cell isolation kits II, respectively (Miltenyi Biotec, Bergisch-Gladbach, Germany) following the manufacturer's instructions. Purity assessed by staining with anti-CD20 or anti-CD4 was $\geq 95 \%$ for both populations. Ramos cells were obtained from the American Type Culture Collection (Rockville, MD).

\section{Cell culture}

pLAg was prepared by suspending promastigotes of the $L$. panamensis strain $\mathrm{MHOM} / \mathrm{COL} / 81 / \mathrm{L} 13$ at a concentration of $1 \times 10^{7}$ parasites $/ \mathrm{mL}$, freezing in liquid nitrogen and thawing at $37^{\circ} \mathrm{C}$ four times. Cells were suspended in RMPI 1640 (Sigma-Aldrich) with 10\% FBS (Gibco, Carlsbad, CA), 2 mM L-glutamine, penicillin $(100 \mathrm{U} / \mathrm{mL})$ and streptomycin $(100 \mathrm{mg} / \mathrm{mL})$ and distributed in 96 well plates in $200 \mu \mathrm{L}$ per well. For PBMC cultures, $4 \times 10^{5} \mathrm{PBMCs}$ and for B cell/CD4 T cell cocultures, $2 \times 10^{5} \mathrm{~B}$ cells or $2 \times 10^{5} \mathrm{~T}$ cells or both cell types were plated per well. Then $8 \mu \mathrm{L}$ of pLAg were added to the appropriate wells to reach a parasite:cell ratio of $0.2: 1$. The cells were incubated for 5 days at $37^{\circ} \mathrm{C}$ with $5 \% \mathrm{CO}_{2}$. Cells and supernatants were harvested for evaluation of cell surface markers and cytokine secretion, respectively.

Ramos cells were cultured in RPMI 1640 with $10 \%$ heatinactivated FBS at a concentration of $10^{6}$ cells $/ \mathrm{mL}$ with pLAg ( $10^{7}$ parasites/mL final concentration), $5 \mu \mathrm{M} \mathrm{CpG}$ ODN 2006 (InvivoGen, San Diego, CA) or no stimulus for
48 hours. Cells were harvested for evaluation of cell surface markers or BCR-mediated endocytosis.

\section{Endocytosis assay}

Ramos cells were incubated with goat $\left.\mathrm{F}(\mathrm{ab})_{2}\right)_{2}$ anti-human IgM-biotin (Invitrogen, Camarillo, CA) at $4{ }^{\circ} \mathrm{C}$ for 20 minutes, washed twice with PBS, resuspended in media and incubated with the Ova Antigen Delivery Reagent (Ova-FITC conjugated to an anti-biotin antibody, Miltenyi Biotec, Bergisch-Gladbach, Germany) at $37^{\circ} \mathrm{C}$ for different time periods, at which cells were harvested and fluorescence evaluated by flow cytometry.

\section{Flow cytometry}

The following antibodies were used for cell surface marker evaluation: anti-CD4-PE-Cy5, anti-CD69-PE, anti-CD127PE-Cy7, anti-CD20-PE-Cy7, anti-CD86-PE, anti-CD80-FITC (eBioscience, San Diego, CA), anti-CD25-ECD, anti-HLADR-ECD, and anti-CD11c-PC5 (Beckman Coulter, Brea, CA). Primary human cells or Ramos cells were suspended in FACS buffer (1× PBS, 1\% BSA, $\left.0.1 \% \mathrm{NaN}_{3}\right)$ and incubated for 20 minutes with panels of the indicated antibodies at $4^{\circ} \mathrm{C}$. After washing, cells were analyzed in a Navios flow cytometer (Beckman Coulter, Brea, CA) and data was analyzed using FlowJo 7.6 software (Tree Star, Inc., Ashland, OR). Gates used for analysis were set using appropriate isotype controls.

\section{Cytokine measurement}

Cytokines were measured in culture supernatants using the Human Th1/Th2/Th9/Th17/Th22 13plex FlowCytomix Multiplex (eBioscience) following the manufacturer's instructions. Data were analyzed using FlowCytomix Pro Software (eBioscience).

\section{Statistical analysis}

The Kolmogorov-Smirnov test was used to determine parametric or non-parametric distribution of the data. Thereafter, for comparisons between healthy subjects and CL patients, parametric data were analyzed using student t-test, and the Mann-Whitney test was applied for non-parametric data. For comparisons between CL patient cell cultures with L. panamensis- and control cultures, parametric and non-parametric data were analyzed using the paired t-test and the Wilcoxon signedrank test, respectively. Statistical significance was defined as $\mathrm{p}<0.05$. All data were analyzed using Prism 5 software (GraphPad Software, Inc., La Jolla, CA).

\section{Results and discussion}

CD4 T cells and B cells of CL patients are concomitantly activated by $L$. panamensis in PBMC cultures

We have previously shown that $L$. panamensis antigens induce CD4 $\mathrm{T}$ cell proliferation and cytokine secretion 
in vitro in CL patients and that immune response profiles differ in relation with clinical outcome; further, responses are specific in that no response to pLAg is observed with cells from uninfected individuals $[5,38,40]$. To determine whether B cells contribute to CD4 T cell activation in the context of active disease, we evaluated the activation of both CD4 T cells and B cells by Leishmania antigens in PBMC cultures. We found that the activation markers CD25 and CD69 were upregulated in CD4 ${ }^{+}$lymphocytes after incubation with pLAg (Figure 1A and B) and that CD4 T cells with the $\mathrm{CD} 25^{\text {hi }} \mathrm{CD} 127^{-}$regulatory phenotype were induced by re-exposure to parasite antigens in vitro (Figure 1A and B). We have previously shown that cells with this regulatory phenotype are increased after treatment of chronic CL in patients from this region [38]. PBMCs from healthy subjects exposed to pLAg showed no activation marker upregulation or increase in the frequency of CD25 ${ }^{\text {hi }}$ CD $127^{-}$cells (Figure $1 B$ ). Thus, the changes in activation/regulatory markers observed in cells from CL patients likely represent the re-activation or expansion of cells specific for Leishmania antigens that were primed in vivo.
To evaluate the potential of B cells as APCs in these cultures, we evaluated the expression of the costimulatory molecules CD86 and CD80 and MHCII molecules (HLA$\mathrm{DR}$ ) in B cells (identified as $\mathrm{CD}_{2} 0^{+}$lymphocytes) compared to DCs (identified as CD11c ${ }^{\text {hi }} \mathrm{FS}^{\text {hi }}$ cells), recognized APCs and potent inducers of the adaptive immune response. As shown in Figure 2A, after 5 days of culture without antigen, DCs showed higher expression of CD86 and HLA-DR than B cells. However, when incubated with pLAg, B cells showed strong upregulation of CD86, while CD80 and HLA-DR underwent no significant changes. Meanwhile, DCs upregulated CD86 to a lesser extent and showed strong upregulation of CD80, but HLA-DR was downregulated (Figure 2). Exposure of cells from healthy subjects to pLAg did not result in significant changes, indicating that priming of cells in vivo was necessary for the observed activation (Figure 2). These results show that B cells specific for Leishmania antigens present in the blood of CL patients are able to attain the costimulatory activities needed for antigen presentation while maintaining MHCII expression. DCs upregulated costimulatory molecules but presented a significant decrease
A
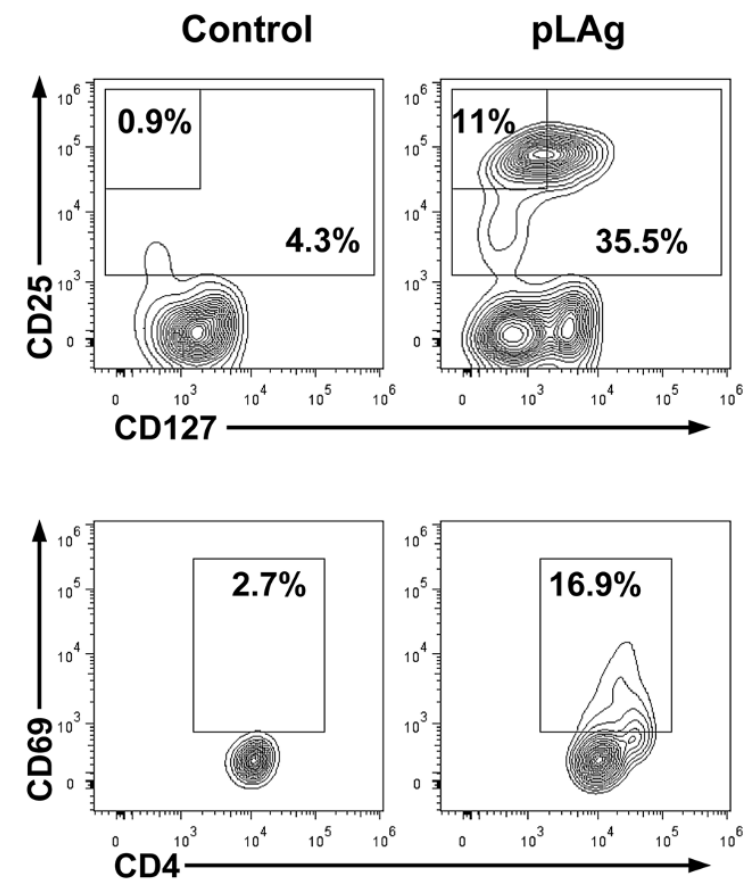

B Healthy subjects

\section{CL patients}
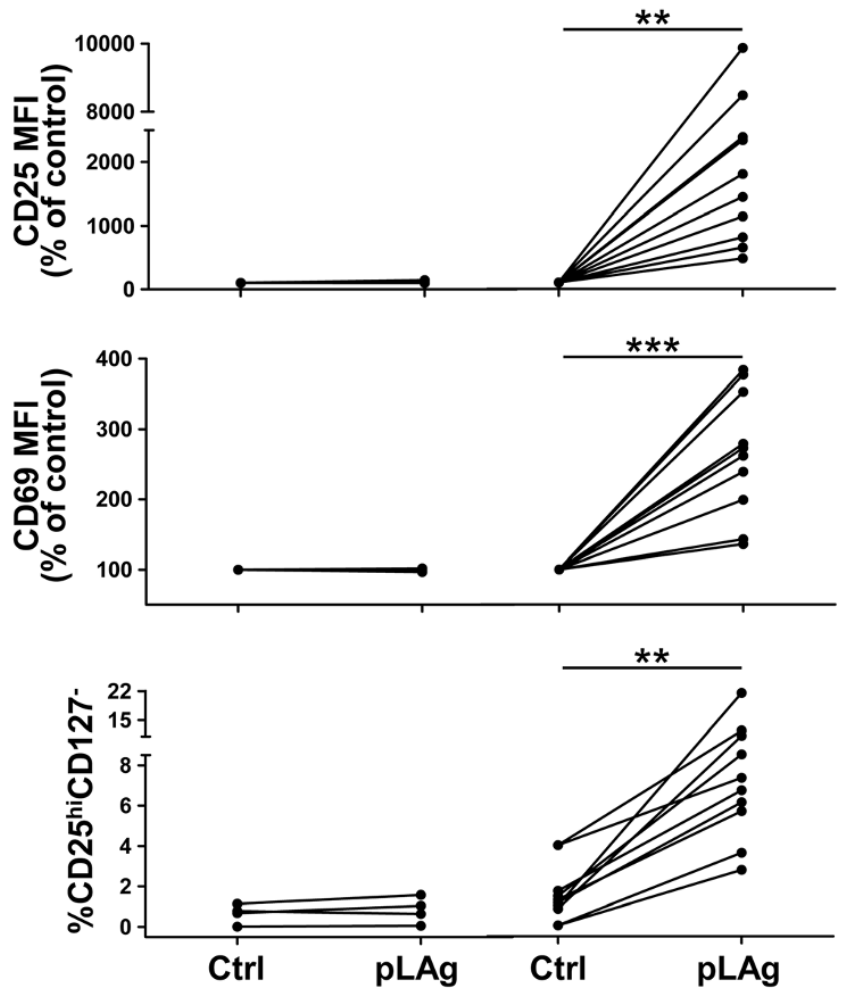

Figure 1 Stimulation with pLAg induces upregulation of activation/regulatory markers in CD4 T cells from CL patients. PBMCs were isolated from peripheral blood of $C L$ patients $(n=10)$ and healthy subjects $(n=4)$, incubated with promastigote $L$. panamensis antigen (pLAg) for 5 days and stained for CD4, CD25, CD127, and CD69. A. Contour plots of cells within the CD4 ${ }^{+}$lymphocyte gate from one representative CL patient showing the effects of pLAg on the expression of CD25, CD127, and CD69. B. Expression of CD25 and CD69, and percentage of CD25 hi CD127 cells within the $\mathrm{CD}^{+}$gate for healthy subjects and $\mathrm{CL}$ patients. ${ }^{* *} \mathrm{p}<0.01$. 


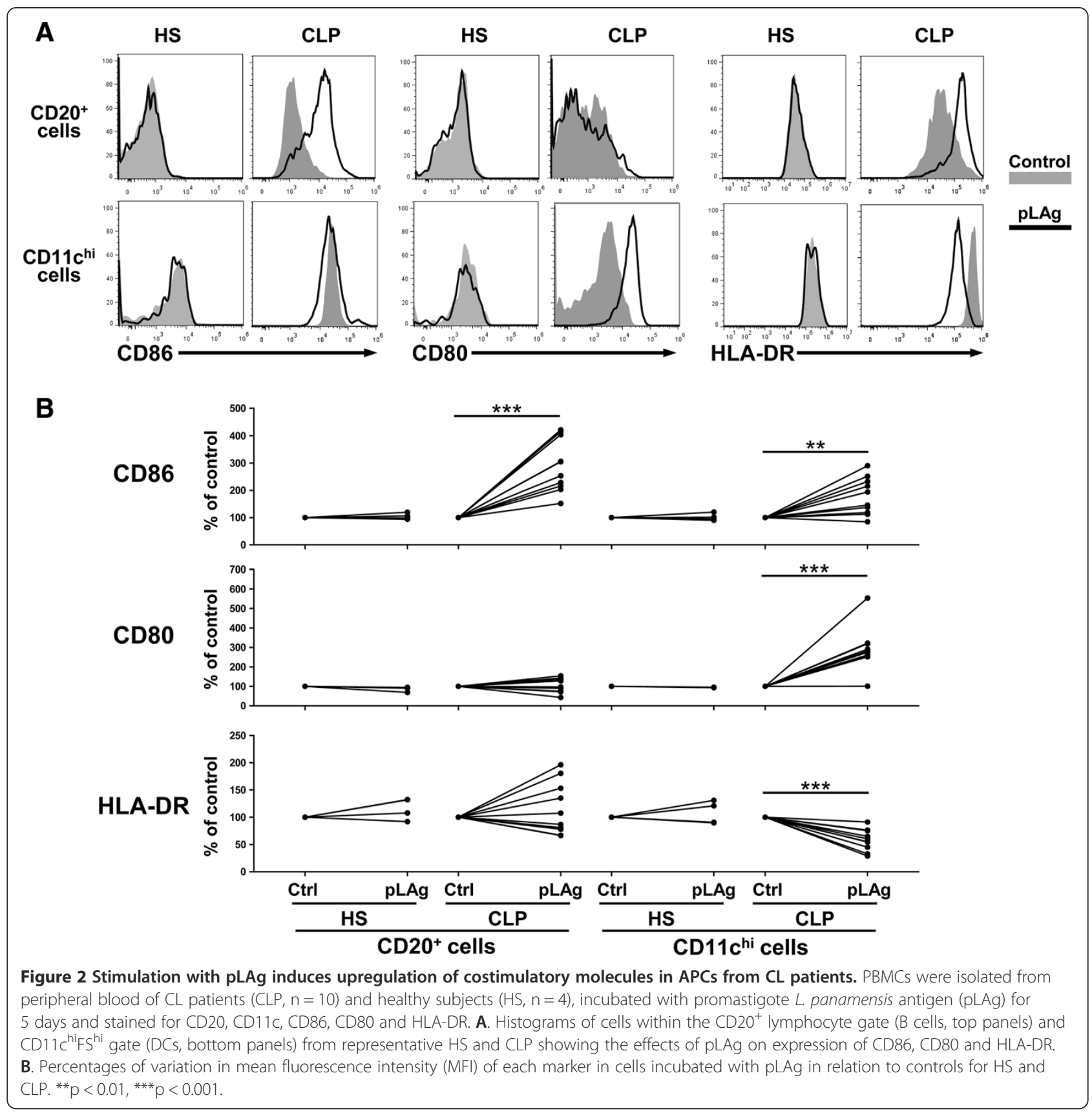

of MHCII expression after interaction with L. panamensis antigens. Even though several reports show downregulation of MHCII molecules after Leishmania infection in both DCs [18,41,42] and macrophages [10,13,43], we are not aware of any studies showing MHCII downregulation in DCs after incubation with soluble Leishmania antigens. Despite this decrease of MHCII, high expression of these molecules was still evident in DCs, indicating that this cell type was also poised to be a competent APC. Since both CD80 and CD86 have been shown to be able to provide the costimulation needed for CD4 T cell activation [44,45], these results allow us to conclude that in these cultures both B cells and DCs had a profile consistent with APC activation.

To establish the cytokine profile induced by L. panamensis in PBMCs from CL patients, we measured 13 cytokines in culture supernatants. We found that incubation with pLAg induced significant levels of IFN- $\gamma$, TNF- $\alpha$, IL-13 and IL-6 (Figure 3). The cytokines IL-10, IL-12p70, IL$1 \beta$, IL-5 and IL-9 were secreted in lower quantities, yet the increase was statistically significant in relation to controls. No significant production of IL-2, IL-17A, IL-4 or IL-22 was induced (Figure 3). This cytokine profile, which includes pro-inflammatory, Th1, Th2 and regulatory 


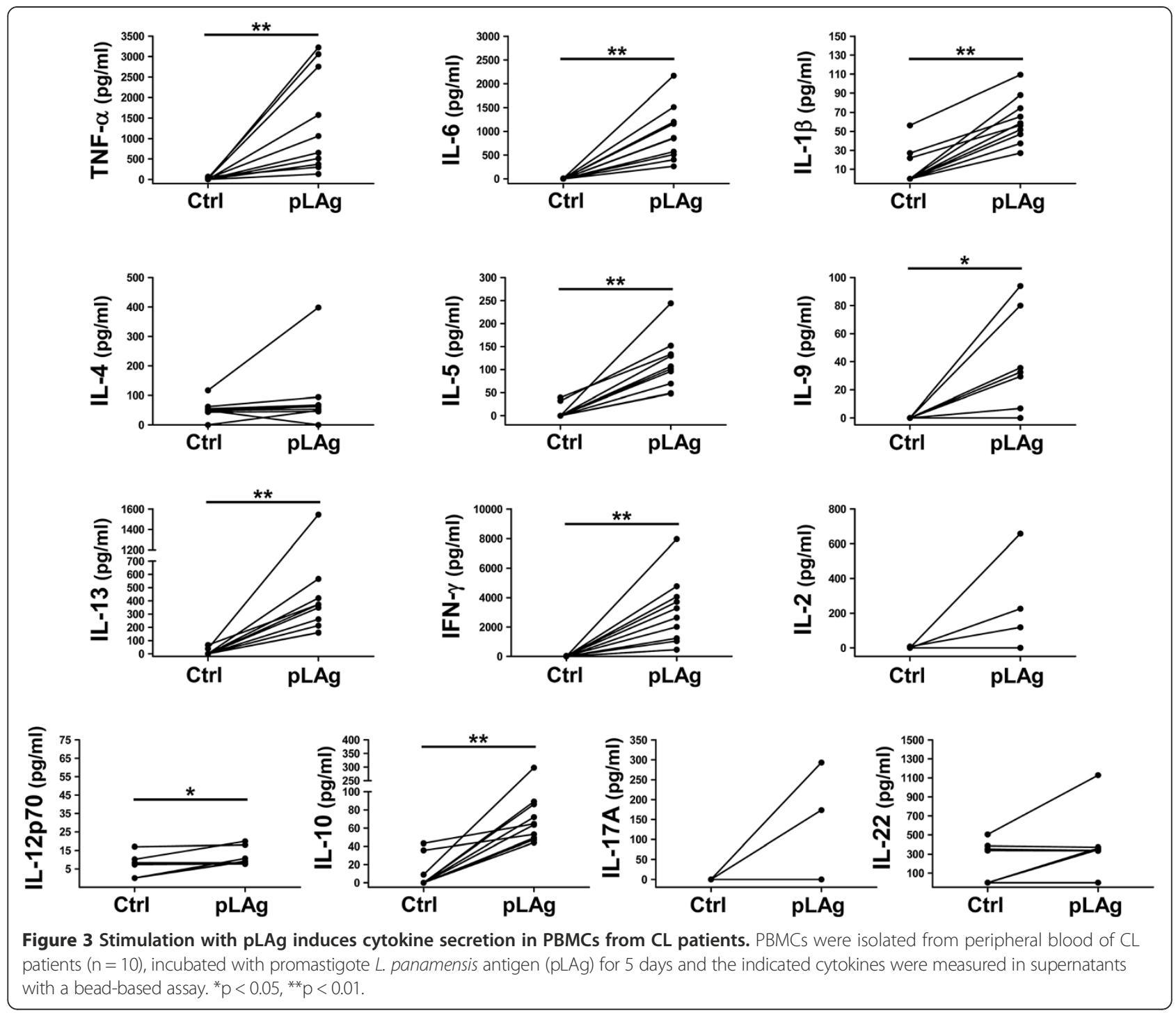

cytokines, is consistent with previous studies of patients from this region [4-8].

\section{Purified B cells are capable of activating CD4 T cells and} inducing cells with a regulatory phenotype in the absence of other APCs

The parallel activation of antigen-specific $B$ cells and CD4 T cells in CL patients suggested that B cells may be able to induce CD4 T cell activation. To test this hypothesis, B cells and CD4 T cells purified from PBMCs of CL patients were stimulated with pLAg. CD25 and CD69 expression were significantly increased in $\mathrm{CD} 4 \mathrm{~T}$ cells when incubated with B cells and pLAg in relation to cells cultured without antigen, or CD4 T cells incubated in the absence of B cells, with or without pLAg (Figure 4A, B and $\mathrm{C}$ ). Although a trend of increased CD69 expression was observed for naïve $\mathrm{T}$ cells in the presence of $\mathrm{pLAg}$, this increase was not significant $(p=0.08)$. Induction of
$\mathrm{CD} 25^{\mathrm{hi}} \mathrm{CD} 127^{-} \mathrm{CD} 4 \mathrm{~T}$ cells was also observed after incubation with $\mathrm{B}$ cells and pLAg and was not evident when either antigen or $B$ cells were absent from cultures (Figure 4A and D). A paired analysis of the net induction of the evaluated $\mathrm{CD} 4 \mathrm{~T}$ cell activation parameters in PBMC or purified B cell/CD4 T cell cultures did not reveal statistically significant differences, corroborating the comparable activation of CD4 T cells by Leishmania specific B cells and PBMCs from CL patients (data not shown).

To evaluate $\mathrm{B}$ cell activation in the B cell/CD4 T cell co-cultures, we analyzed CD86, CD80 and HLA-DR expression. pLAg did not activate $\mathrm{B}$ cells in the absence of CD4 T cells, but strong CD86 upregulation was induced when CD4 $\mathrm{T}$ cells and pLAg were present (Figure 5A). In concurrence with the PBMC cultures, addition of pLAg to purified B cell/CD4 T cells did not result in CD80 or HLA-DR upregulation (Figure 5B and C). These results 


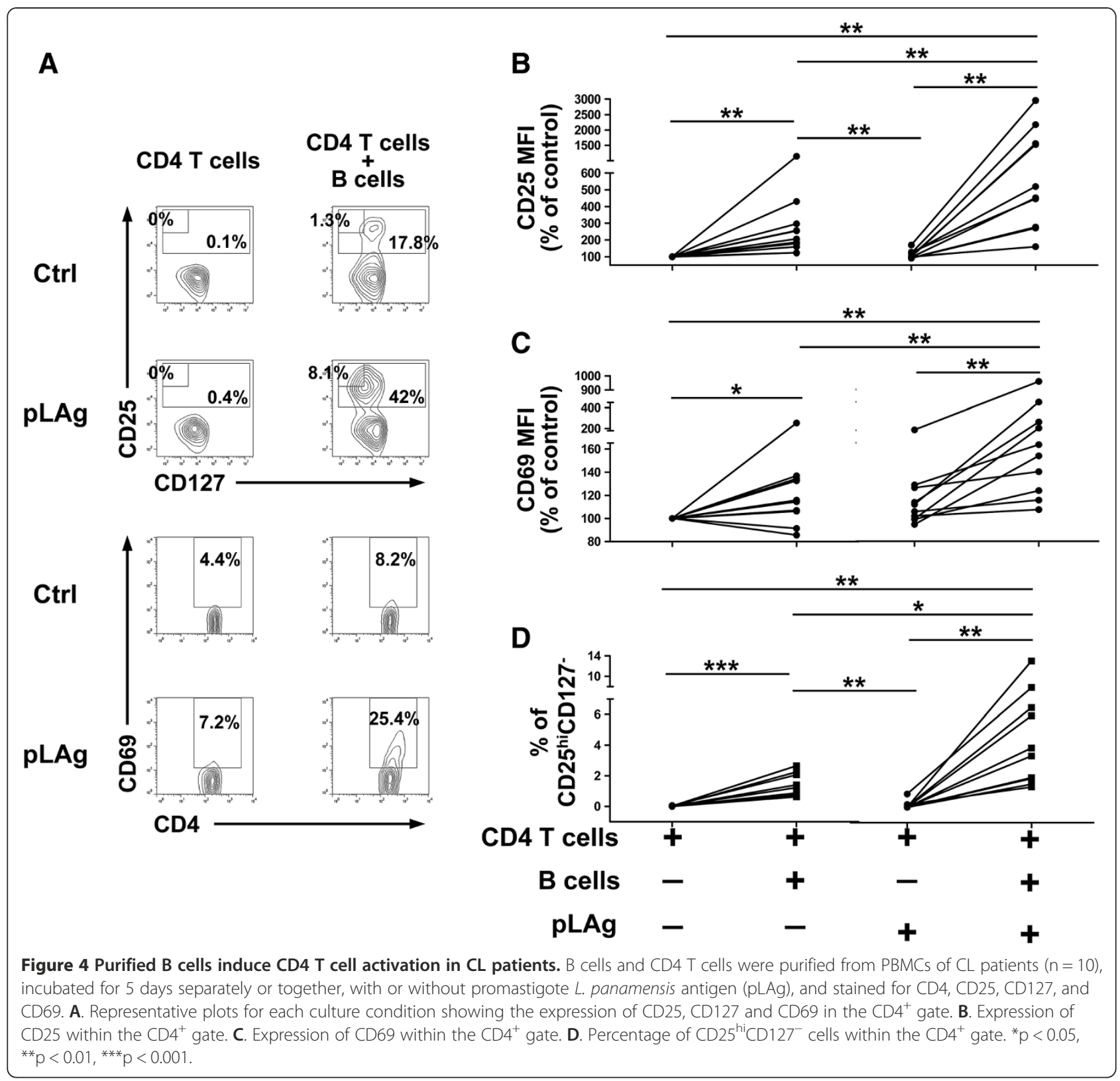

demonstrate that to become competent CD4 activating cells, B cells require the presence of $\mathrm{CD} 4 \mathrm{~T}$ cells. This likely reflects the need for costimulatory ligands expressed by activated CD4 T cells such as CD154 and cytokines $[31,32]$. We also determined the cytokine profile induced by $L$. panamensis antigens in $\mathrm{B}$ cell/CD4 $\mathrm{T}$ cell cocultures. pLAg induced significant secretion of IFN- $\gamma$, TNF- $\alpha$, IL-6, IL-13, IL-5, IL-9, IL-10 and IL-2, while no significant amounts of IL-12p70, IL-1 $\beta$, IL-17A, IL-4 or IL-22 were detected (Figure 6). Importantly, no significant secretion of any cytokine was observed when either CD4 T cells or B cells were incubated alone with pLAg (Figure 6).
These results demonstrate that the capacity of isolated B cells from CL patients to activate CD4 T cells is similar to that of all APCs present in PBMCs. We performed a paired analysis to compare the net increase for each CD4 $\mathrm{T}$ cell activation parameter between PBMC and B cell/CD4 $\mathrm{T}$ cell cultures and found no significant differences. Likewise, net cytokine secretion did not reveal significant differences except for IL-12p70 and IL-1 $\beta$ (which were secreted in low albeit significant amounts only in PBMC cultures), IL-6 (which was secreted in both types of cultures but in significant larger amounts in PBMC cultures) and IL-2 (which was only secreted in $\mathrm{B}$ cell/CD4 T cell cultures). Thus, 10 of the 13 cytokines 


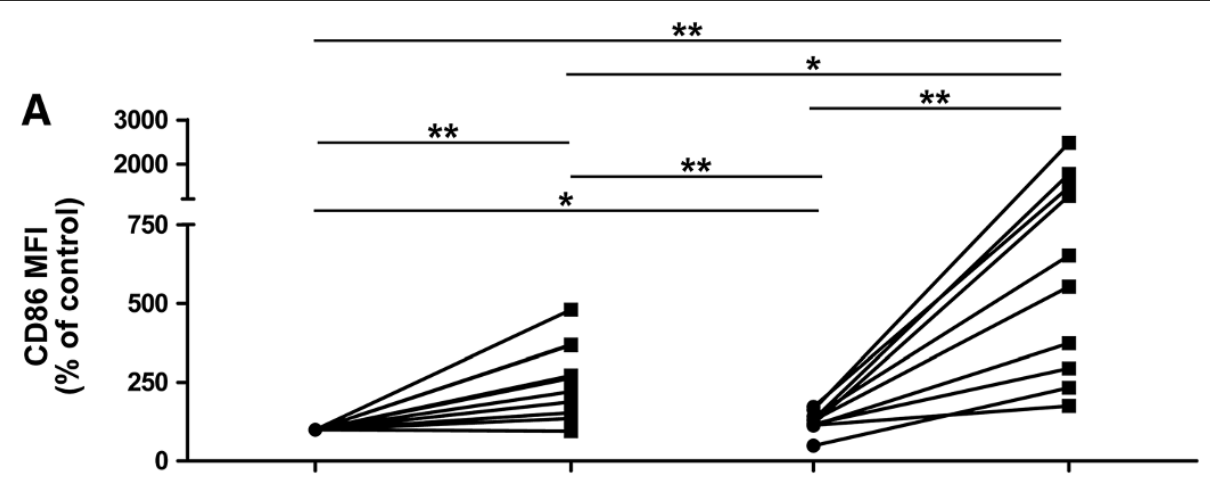

$\mathbf{B}$
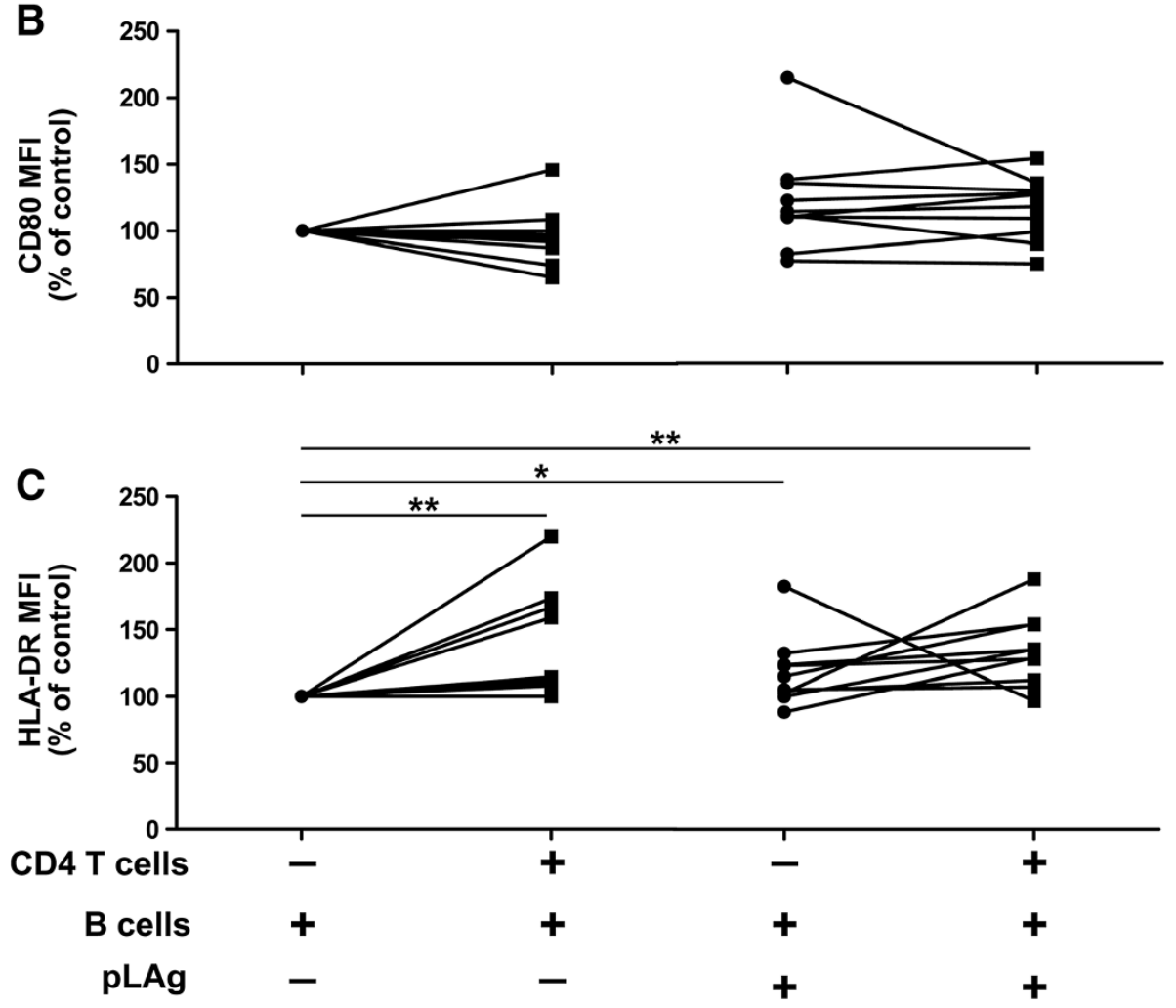

Figure 5 B cells upregulate CD86 in the presence of CD4 T cells. B cells and CD4 T cells were purified from PBMCs of CL patients $(n=10)$, incubated for 5 days separately or together, with or without promastigote L. panamensis antigen (pLAg), and stained for CD20, CD86, CD80, and HLA-DR. A. Expression of CD86 within the $C D 20^{+}$gate. B. Expression of $C D 80$ within the $C D 20^{+}$gate. $\mathbf{C}$. Expression of HLA-DR within the CD20 gate. ${ }^{*} p<0.05,{ }^{* *} p<0.01$.

measured had similar levels in both types of cultures in spite of the fact that PBMCs contain several cytokineproducing cell types besides $\mathrm{B}$ cells and CD4 T cells. The differences observed in IL-12p70, IL-1 $\beta$ and IL- 6 can be explained by the presence of mononuclear phagocytes in PBMCs that are known sources of these cytokines. Significant IL-2 production only in B cell/CD4 T cell cultures suggests that secretion of this cytokine is efficiently induced by interaction of these cell types.

The known mechanisms for CD4 $\mathrm{T}$ cell activation by $\mathrm{T}$ cells are antigen presentation and cytokine secretion.
Since B cells stimulated with pLAg did not produce any significant amount of 13 cytokines that are prominent in antigen induced recall responses, our data strongly suggest that presentation of $L$. panamensis antigens by $\mathrm{B}$ cells is responsible for $\mathrm{CD} 4 \mathrm{~T}$ cell activation. B cells can encounter soluble antigen soon after its entry into the body by several mechanisms and internalize it efficiently by BCR-mediated endocytosis [46]. Therefore, the fact that $\mathrm{B}$ cells are not phagocytic cells, and thus not a natural cellular host for Leishmania, does not diminish the relevance of their CD4 $\mathrm{T}$ cell activation function in $\mathrm{CL}$. 


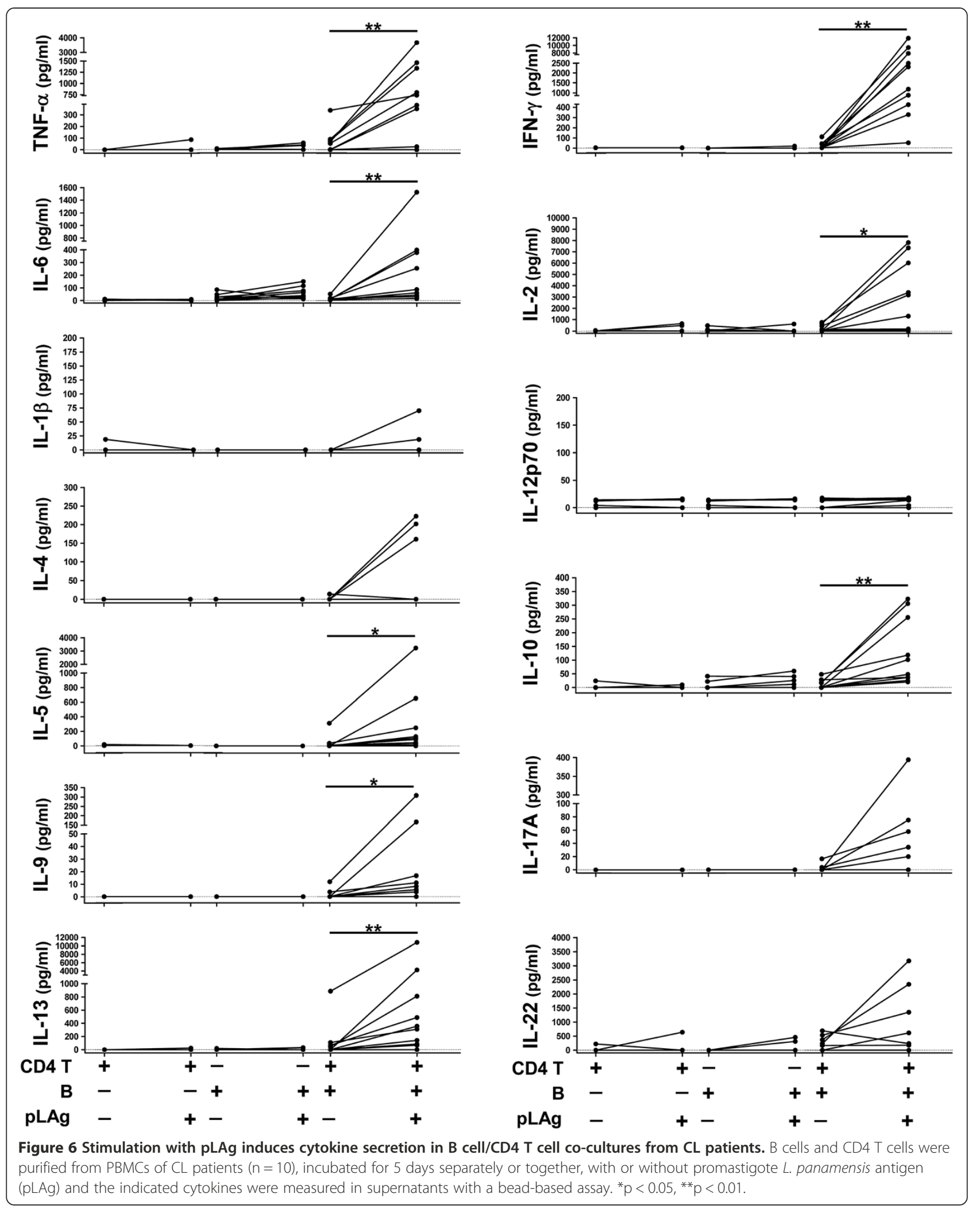


On the contrary, this characteristic may be crucial for their role as APCs in this disease since processing and presentation of particulate antigens on MHCII requires phagosome maturation, a process that can be inhibited by Leishmania [47], whereas presentation of soluble antigens on MHCII requires their correct targeting by the endocytic receptor, a process that is highly efficient after BCR-mediated endocytosis [30,48]. Accordingly, a study by Carvalho et al. found that DCs that were infected by L. braziliensis did not upregulate costimulatory and MHCII molecules, while bystander DCs were activated and presented soluble antigen efficiently [18]. An earlier study by Fruth et al. also showed that infection of macrophages with $L$. major inhibited APC function, but pulsing with Leishmania antigens did not [9]. Consequently, since infection of APCs with live parasites inhibits their function, APCs such as B cells that do not harbor the parasite and are capable of handling soluble antigens may be ideally poised to activate the immune response.

Cultures of purified lymphocytes from CL patients also showed a small but significant increase in the expression of $\mathrm{CD} 25$ and $\mathrm{CD} 69$ and in the frequency of $\mathrm{CD} 25^{\mathrm{hi}} \mathrm{CD} 127^{-}$ cells among CD4 $\mathrm{T}$ cells when these cells were co-cultured with $B$ cells in the absence of pLAg (Figure 4B-D). We also found a significant induction of CD86 and HLA-DR in B cells under the same conditions (Figure 5A and C). These results suggest that non-cognate interactions between $\mathrm{B}$ cells and CD4 T cells can generate activating signals in this setting. The induction of homeostatic lymphocyte proliferation by MHCII/self-peptide presented by APCs is well documented $[32,49,50]$. Hence, the activation observed in $\mathrm{B}$ cell/CD4T cell cultures in the absence of antigen may represent this type of interaction. Alternatively, the activation found in the absence of added antigen may be due to $B$ cells from infected individuals already being loaded with Leishmania antigens, since we have found evidence of parasites in blood, during active CL and even after treatment of the disease [51].

\section{Treatment with $L$. panamensis upregulates MHCII and} costimualtory molecules independently of $B C R$ signaling and enhances BCR-mediated endocytosis in human B cells $\mathrm{BCR}$ mediated endocytosis is one of the key processes that allow B cells to become potent APCs. Therefore, we next evaluated whether $L$. panamensis antigen enhances this process. For this purpose, we used a model in which both antigen and B cells would interact in a uniform manner. Since the number and specificity of B cells primed by Leishmania infection in vivo are uncertain, we did not use primary cells from CL patients. Rather, we used Ramos cells, a human B cell line derived from a lymphoma that expresses surface IgM not specific for Leishmania antigens. We first evaluated if upregulation of costimulatory and MHC molecules could be achieved after treating Ramos cells with
pLAg. Because Ramos cells express TLR9, we used CpG as a positive control of a BCR-independent activation signal. We found that the pLAg at the 0.2 parasites: 1 cell ratio we used in cultures of primary cells did not induce a detectable response (data not shown). To detect a significant effect, we had to increase the parasite antigen concentration 50fold. At a ratio of 10 parasites: 1 cell, increased expression of CD86, CD80 and HLA-DR was observed after 48 hours of culture to levels comparable to those induced by $\mathrm{CpG}$ (Figure 7A and B). Thus, L. panamensis antigen can induce upregulation of activation markers in Ramos cells without BCR engagement.

To test the effect of L. panamensis antigen on BCRmediated endocytosis in Ramos cells, we targeted the model antigen ovalbumin (Ova) to the BCR using an anti-IgM antibody. BCR-mediated endocytosis of fluorescent Ova was evaluated in cells previously cultured for 48 hours with pLAg or CpG or without stimulus, as described in Materials and Methods. We found that Ova endocytosis by Ramos cells increased over the first two hours and then reached a plateau. When these cells were treated with $\mathrm{CpG}$ or $\mathrm{pLAg}$, Ova endocytosis was more efficient and continued to increase throughout the period of evaluation (Figure $7 \mathrm{C}$ and D). A statistically significant difference was detected for both pLAg and CpG when compared to untreated cells both with respect to fluorescence intensity and the percentage of Ova-FITC positive cells at the 1 hour time point (Figure 7E). When OVA antigen was not targeted to the $\mathrm{BCR}$, fluorescence did not increase at any time point, confirming that the assay evaluated BCRmediated endocytosis (Figure 7D). This experimental strategy allowed us to show that L. panamensis antigen promotes specific antigen uptake by human B cells. The expression of surface IgM did not change significantly after treatment with CpG or pLAg (data not shown), indicating that the enhanced endocytosis was not due to the availability of more internalizing receptors. Similar enhancement of Ova endocytosis was previously observed in DCs incubated with L. braziliensis antigens for four days [18].

These results demonstrate that $L$. panamensis antigen can induce activation of $B$ cell antigen presenting function without BCR engagement. TLR9 is the innate immune receptor that has the highest expression on human B cells [52-54] and it can be stimulated by Leishmania DNA [55,56]. Since the pLAg preparation includes the parasite DNA, it is likely that TLR9 signaling can mediate activation of the antigen presenting function of human B cells, a question that we will address in future studies. In humans, B cells and plasmacytoid DCs are the only cell types responsive to TLR9 $[57,58]$. Because the antigen presenting capacity of plasmacytoid DCs is low [59] and is further downregulated by TLR9 signaling [60], B cells constitute 


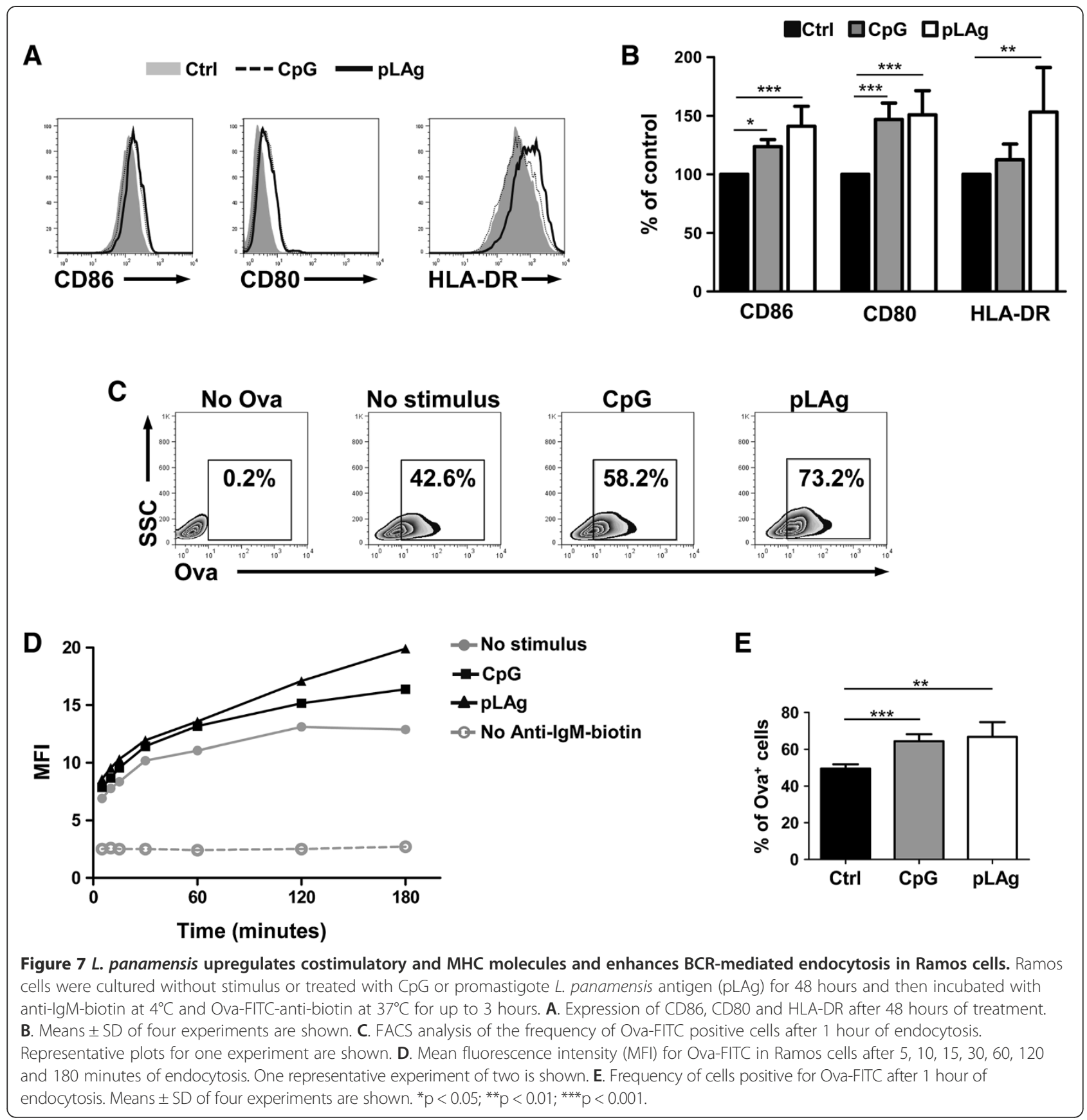

the primary APC targeted by TLR9 ligands in humans. In light of the numerous examples of successful protection in animals using $\mathrm{CpG}$ as adjuvant in vaccination strategies for CL [61-64], defining the role of TLR9 in B cell antigen presentation is critical to develop efficient strategies that can be translated into clinical applications.

\section{Conclusions}

We have shown that B cells from the peripheral blood of CL patients are capable of inducing CD4 T cell activation and cytokine secretion, an effect likely mediated by antigen presentation. The CD4 $\mathrm{T}$ cell activating capacity of these B cells was similar in both quantity and quality to that observed after incubation with all cells present in PBMCs. These B cells represent an attractive target for immunomodulatory strategies that aim to redirect the host's immune response to a healing phenotype in chronic Leishmania (Viannia) infections.

\section{Abbreviations}

CL: Cutaneous leishmaniasis; APCs: Professional antigen presenting cells; DCs: Dendritic cells; PBMCs: Peripheral blood mononuclear cells; pLAg: Promastigote L. panamensis antigen. 


\section{Competing interests}

The authors declare that they have no competing interests.

\section{Authors' contributions}

All authors participated in conception and design of the study and data interpretation. DR-P performed the experiments and wrote the manuscript. NGS and DM-P critically reviewed and and contributed to the writing of the manuscript. All authors reviewed and approved the final version of the manuscript.

\section{Authors' information}

Dr. Rodriguez-Pinto's current address: Facultad de Medicina, Facultad de Ciencias de la Salud, Universidad de las Américas, Quito, Ecuador.

\section{Acknowledgements}

We thank Liliana Valderrama and Alexandra Cossio for coordination of the study, Olga Fernández, Laura González and Karen Goldsmith-Pestana for technical assistance, Wilson Cortez, Eduardo Ortiz, Lyda Cuervo, Ricardo Márquez, María del Mar Castro, Javier Martínez and Jimena Jojoa for patient evaluation and recruitment, and Beatriz Herrera for assistance with bibliography. This work was supported by Fogarty International Center (NIH) (grant number D43 TW006589), the United States National Institutes of Health (NIH), National Institute of Allergy and Infectious Diseases (grant number 1R01Al093775) and the 2011 Gorgas Memorial Institute Research Award to D.R-P. The funders had no role in study design, data collection and analysis, decision to publish, or preparation of the manuscript.

\section{Author details}

${ }^{1}$ Centro Internacional de Entrenamiento e Investigaciones Médicas (CIDEIM), Cali, Colombia. ${ }^{2}$ Yale University School of Public Health, New Haven, CT, USA. ${ }^{3}$ Current Address: Facultad de Medicina, Facultad de Ciencias de la Salud, Universidad de las Américas, Quito, Ecuador.

Received: 8 January 2014 Accepted: 21 February 2014

Published: 25 February 2014

\section{References}

1. Murray HW, Berman JD, Davies CR, Saravia NG: Advances in leishmaniasis. Lancet 2005, 366:1561-1577.

2. Bogdan C: Leishmaniasis in rheumatology, haematology and oncology: epidemiological, immunological and clinical aspects and caveats. Ann Rheum Dis 2012, 71(Suppl 2):i60-i66.

3. Sacks $D$, Noben-Trauth $\mathrm{N}$ : The immunology of susceptibility and resistance to Leishmania major in mice. Nat Rev Immunol 2002, 2:845-858.

4. Castilho TM, Goldsmith-Pestana K, Lozano C, Valderrama L, Saravia NG, McMahon-Pratt D: Murine model of chronic L. (Viannia) panamensis infection: role of IL-13 in disease. Eur J Immunol 2010, 40:2816-2829.

5. Díaz YR, Rojas R, Valderrama L, Saravia NG: T-bet, GATA-3, and Foxp3 expression and Th1/Th2 cytokine production in the clinical outcome of human infection with Leishmania (Viannia) species. J Infect Dis 2010 202:406-415.

6. Pirmez C, Yamamura M, Uyemura K, Paes-Oliveira M, Conceição-Silva F Modlin RL: Cytokine patterns in the pathogenesis of human leishmaniasis. J Clin Invest 1993, 91:1390-1395.

7. de Assis Souza M, de Castro MC B, de Oliveira AP, de Almeida AF, de Almeida TM, Reis LC, Medeiros AC, de Brito ME, Pereira VR: Cytokines and $\mathrm{NO}$ in American tegumentary leishmaniasis patients: Profiles in active disease, after therapy and in self-healed individuals. Microb Pathog 2013 57C:27-32.

8. de Oliveira $\mathrm{Cl}$, Brodskyn Cl: The immunobiology of Leishmania braziliensis infection. Front Immunol 2012, 3:145

9. Fruth U, Solioz N, Louis JA: Leishmania major interferes with antigen presentation by infected macrophages. J Immunol 1993, 150:1857-1864.

10. De Almeida MC, Cardoso SA, Barral-Netto M: Leishmania (Leishmania) chagasi infection alters the expression of cell adhesion and costimulatory molecules on human monocyte and macrophage. Int J Parasitol 2003, 33:153-162.

11. Cameron P, McGachy A, Anderson M, Paul A, Coombs GH, Mottram JC, Alexander J, Plevin R: Inhibition of lipopolysaccharide-induced macrophage IL-12 production by Leishmania mexicana amastigotes: the role of cysteine peptidases and the NF-KB signaling pathway. J Immunol 2004, 173:3297-3304

12. Weinheber $N$, Wolfram M, Harbecke D, Aebischer T: Phagocytosis of Leishmania mexicana amastigotes by macrophages leads to a sustained suppression of IL-12 production. Eur J Immunol 1998, 28:2467-2477.

13. von Stebut E, Belkaid Y, Jakob T, Sacks DL, Udey MC: Uptake of Leishmania major amastigotes results in activation and interleukin 12 release from murine skin-derived dendritic cells: implications for the initiation of anti-Leishmania immunity. J Exp Med 1998, 188:1547-1552.

14. Prina E, Abdi SZ, Lebastard M, Perret E, Winter N, Antoine JC: Dendritic cells as host cells for the promastigote and amastigote stages of Leishmania amazonensis: the role of opsonins in parasite uptake and dendritic cell maturation. I Cell Sci 2004 , 117:315-325.

15. Bennett CL, Misslitz A, Colledge L, Aebischer T, Blackburn CC: Silent infection of bone marrow-derived dendritic cells by Leishmania mexicana amastigotes. Eur J Immunol 2001, 31:876-883.

16. Aebischer T, Bennett CL, Pelizzola M, Vizzardelli C, Pavelka N, Urbano M, Capozzoli M, Luchini A, llg T, Granucci F, Blackburn CC, Ricciardi-Castagnoli P: A critical role for lipophosphoglycan in proinflammatory responses of dendritic cells to Leishmania mexicana. Eur J Immunol 2005, 35:476-486.

17. Petritus PM, Manzoni-de-Almeida D, Gimblet C, Gonzalez Lombana C, Scott $P$ : Leishmania mexicana induces limited recruitment and activation of monocytes and monocyte-derived dendritic cells early during infection. PLoS Negl Trop Dis 2012, 6:e1858.

18. Carvalho LP, Pearce EJ, Scott P: Functional dichotomy of dendritic cells following interaction with Leishmania braziliensis: infected cells produce high levels of TNF-alpha, whereas bystander dendritic cells are activated to promote T cell responses. J Immunol 2008, 181:6473-6480.

19. Guarín N, Palma Gl, Pirmez C, Valderrama L, Tovar R, Saravia NG: Comparative immunohistological analysis of the Montenegro skin test reaction in asymptomatic infection and in acute and chronic cutaneous leishmaniasis. Biomedica 2006, 26(Suppl 1):38-48.

20. Palma Gl, Saravia NG: In situ characterization of the human host response to Leishmania panamensis. Am J Dermatopathol 1997, 19:585-590.

21. Bomfim G, Andrade BB, Santos S, Clarêncio J, Barral-Netto M, Barral A: Cellular analysis of cutaneous leishmaniasis lymphadenopathy: insights into the early phases of human disease. Am J Trop Med Hyg 2007, 77:854-859.

22. Rossi-Bergmann B, Müller I, Godinho EB: TH1 and TH2 T-cell subsets are differentially activated by macrophages and $B$ cells in murine leishmaniasis. Infect Immun 1993, 61:2266-2269.

23. Bankoti R, Gupta K, Levchenko A, Stäger S: Marginal zone B cells regulate antigen-specific T cell responses during infection. J Immunol 2012, 188:3961-3971.

24. Gibson-Corley KN, Boggiatto PM, Bockenstedt MM, Petersen CA, Waldschmidt TJ, Jones DE: Promotion of a functional B cell germinal center response after Leishmania species co-infection is associated with lesion resolution. Am J Pathol 2012, 180:2009-2017.

25. Deak E, Jayakumar A, Cho KW, Goldsmith-Pestana K, Dondji B, Lambris JD, McMahon-Pratt D: Murine visceral leishmaniasis: IgM and polyclonal B-cell activation lead to disease exacerbation. Eur J Immunol 2010, 40:1355-1368.

26. Gibson-Corley KN, Boggiatto PM, Mukbel RM, Petersen CA, Jones DE: A deficiency in the $B$ cell response of $C 57 B L / 6$ mice correlates with loss of macrophage-mediated killing of Leishmania amazonensis. Int J Parasitol 2010, 40:157-161.

27. Ronet C, Hauyon-La Torre Y, Revaz-Breton M, Mastelic B, Tacchini-Cottier F, Louis J, Launois P: Regulatory B cells shape the development of Th2 immune responses in BALB/c mice infected with Leishmania major through IL-10 production. J Immunol 2010, 184:886-894.

28. Ronet $\mathrm{C}$, Voigt H, Himmelrich H, Doucey MA, Hauyon-La Torre $Y$, Revaz Breton M, Tacchini-Cottier F, Bron C, Louis J, Launois P: Leishmania majorspecific $B$ cells are necessary for Th2 cell development and susceptibility to L. major LV39 in BALB/c mice. J Immunol 2008, 180:4825-4835.

29. Wanasen $N$, Xin L, Soong L: Pathogenic role of B cells and antibodies in murine Leishmania amazonensis infection. Int J Parasitol 2008, 38:417-429.

30. Vascotto F, Le Roux D, Lankar D, Faure-André G, Vargas P, Guermonprez P, Lennon-Duménil AM: Antigen presentation by B lymphocytes: how receptor signaling directs membrane trafficking. Curr Opin Immunol 2007, 19:93-98.

31. Rodríguez-Pinto D, Moreno J: B cells can prime naive $C D 4^{+} \mathrm{T}$ cells in vivo in the absence of other professional antigen-presenting cells in a CD154-CD40-dependent manner. Eur J Immunol 2005, 35:1097-1105. 
32. Parker DC: T cell-dependent B cell activation. Annu Rev Immunol 1993, $11: 331-360$

33. Rodríguez-Pinto D: B cells as antigen presenting cells. Cell Immunol 2005, 238:67-75.

34. Constant S, Schweitzer N, West J, Ranney P, Bottomly K: B lymphocytes can be competent antigen-presenting cells for priming $\mathrm{CD}^{+} \mathrm{T}$ cells to protein antigens in vivo. $J$ Immunol 1995, 155:3734-3741.

35. Molnarfi N, Schulze-Topphoff U, Weber MS, Patarroyo JC, Prod'homme T, Varrin-Doyer M, Shetty A, Linington C, Slavin AJ, Hidalgo J, Jenne DE, Wekerle H, Sobel RA, Bernard CC, Shlomchik MJ, Zamvil SS: MHC class II-dependent B cell APC function is required for induction of CNS autoimmunity independent of myelin-specific antibodies. J Exp Med 2013, 210:2921-2937.

36. Lund FE: Cytokine-producing B lymphocytes-key regulators of immunity. Curr Opin Immunol 2008, 20:332-338.

37. Corredor A, Kreutzer RD, Tesh RB, Boshell J, Palau MT, Caceres E, Duque S, Pelaez D, Rodriquez G, Nichols S, Hernandez CA, Morales A, Young DG, Ferro C: Distribution and etiology of leishmaniasis in Colombia. Am J Trop Med Hyg 1990, 42:206-214

38. Rodriguez-Pinto D, Navas A, Blanco VM, Ramírez L, Garcerant D, Cruz A, Craft N, Saravia NG: Regulatory T cells in the pathogenesis and healing of chronic human dermal leishmaniasis caused by Leishmania (Viannia) species. PLoS Negl Trop Dis 2012, 6:e1627.

39. Bosque F, Saravia NG, Valderrama L, Milon G: Distinct innate and acquired immune responses to Leishmania in putative susceptible and resistant human populations endemically exposed to L. (Viannia) panamensis infection. Scand J Immunol 2000, 51:533-541.

40. Saravia NG, Valderrama L, Labrada M, Holguín AF, Navas C, Palma G, Weigle KA: The relationship of Leishmania braziliensis subspecies and immune response to disease expression in New World leishmaniasis. J Infect Dis 1989, 159:725-735

41. Leite PM, Gomes RS, Figueiredo AB, Serafim TD, Tafuri WL, de Souza CC, Moura SA, Fietto JL, Melo MN, Ribeiro-Dias F, Oliveira MA, Rabello A, Afonso LC: Ecto-nucleotidase activities of promastigotes from Leishmania (Viannia) braziliensis relates to parasite infectivity and disease clinical outcome. PLoS Negl Trop Dis 2012, 6:e1850.

42. Figueiredo AB, Serafim TD, Marques-da-Silva EA, Meyer-Fernandes JR, Afonso LC: Leishmania amazonensis impairs DC function by inhibiting CD40 expression via A2B adenosine receptor activation. Eur J Immunol 2012, 42:1203-1215

43. De Souza Leao S, Lang T, Prina E, Hellio R, Antoine JC: Intracellular Leishmania amazonensis amastigotes internalize and degrade MHC class II molecules of their host cells. J Cell Sci 1995, 108:3219-3231.

44. Lanier LL, O'Fallon S, Somoza C, Phillips JH, Linsley PS, Okumura K, Ito D, Azuma M: CD80 (B7) and CD86 (B70) provide similar costimulatory signals for $\mathrm{T}$ cell proliferation, cytokine production, and generation of CTL. J Immunol 1995, 154:97-105.

45. Lim TS, Goh JK, Mortellaro A, Lim CT, Hämmerling GJ, Ricciardi-Castagnoli P: CD80 and CD86 differentially regulate mechanical interactions of T-cells with antigen-presenting dendritic cells and B-cells. PLoS One 2012, 7:e45185.

46. Batista FD, Harwood NE: The who, how and where of antigen presentation to B cells. Nat Rev Immunol 2009, 9:15-27.

47. Desjardins M, Descoteaux A: Inhibition of phagolysosomal biogenesis by the Leishmania lipophosphoglycan. J Exp Med 1997, 185:2061-2068.

48. Burgdorf S, Kurts C: Endocytosis mechanisms and the cell biology of antigen presentation. Curr Opin Immunol 2008, 20:89-95.

49. Do JS, Min B: Differential requirements of $\mathrm{MHC}$ and of DCs for endogenous proliferation of different T-cell subsets in vivo. Proc Natl Acad Sci U S A 2009, 106:20394-20398.

50. Kirberg J, Berns A, von Boehmer H: Peripheral T cell survival requires continual ligation of the $T$ cell receptor to major histocompatibility complex-encoded molecules. J Exp Med 1997, 186:1269-1275.

51. Vergel C, Palacios R, Cadena H, Posso CJ, Valderrama L, Perez M, Walker J, Travi BL, Saravia NG: Evidence for Leishmania (Viannia) parasites in the skin and blood of patients before and after treatment. J Infect Dis 2006 , 194:503-511.

52. Bernasconi NL, Onai N, Lanzavecchia A: A role for Toll-like receptors in acquired immunity: up-regulation of TLR9 by BCR triggering in naive $B$ cells and constitutive expression in memory B cells. Blood 2003, 101:4500-4504
53. Hanten JA, Vasilakos JP, Riter CL, Neys L, Lipson KE, Alkan SS, Birmachu W: Comparison of human B cell activation by TLR7 and TLR9 agonists. BMC Immunol 2008, 9:39

54. Dasari P, Nicholson IC, Hodge G, Dandie GW, Zola H: Expression of toll-like receptors on B lymphocytes. Cell Immunol 2005, 236:140-145.

55. Liese J, Schleicher U, Bogdan C: TLR9 signaling is essential for the innate NK cell response in murine cutaneous leishmaniasis. Eur J Immunol 2007, 37:3424-3434.

56. Abou Fakher FH, Rachinel N, Klimczak M, Louis J, Doyen N: TLR9dependent activation of dendritic cells by DNA from Leishmania major favors Th1 cell development and the resolution of lesions. J Immunol 2009, 182:1386-1396.

57. Hornung V, Rothenfusser S, Britsch S, Krug A, Jahrsdörfer B, Giese T, Endres S, Hartmann G: Quantitative expression of toll-like receptor 1-10 mRNA in cellular subsets of human peripheral blood mononuclear cells and sensitivity to CpG oligodeoxynucleotides. J Immunol 2002, 168:4531-4537.

58. Kadowaki N, Ho S, Antonenko S, Malefyt RW, Kastelein RA, Bazan F, Liu YJ: Subsets of human dendritic cell precursors express different toll-like receptors and respond to different microbial antigens. J Exp Med 2001, 194:863-869.

59. Colonna M, Trinchieri G, Liu YJ: Plasmacytoid dendritic cells in immunity. Nat Immunol 2004, 5:1219-1226.

60. Benitez-Ribas D, Tacken P, Punt CJ, de Vries IJ, Figdor CG: Activation of human plasmacytoid dendritic cells by TLR9 impairs FcyRll-mediated uptake of immune complexes and presentation by MHC class II. J Immunol 2008, 181:5219-5224.

61. Flynn B, Wang V, Sacks DL, Seder RA, Verthelyi D: Prevention and treatment of cutaneous leishmaniasis in primates by using synthetic type D/A oligodeoxynucleotides expressing CpG motifs. Infect Immun 2005, 73:4948-4954

62. Ramírez L, Iborra S, Cortés J, Bonay P, Alonso C, Barral-Netto M, Soto M: $\mathrm{BALB} / \mathrm{c}$ mice vaccinated with Leishmania major ribosomal proteins extracts combined with $\mathrm{CpG}$ oligodeoxynucleotides become resistant to disease caused by a secondary parasite challenge. J Biomed Biotechnol 2010, 2010:181690.

63. Wu W, Weigand L, Belkaid Y, Mendez S: Immunomodulatory effects associated with a live vaccine against Leishmania major containing CpG oligodeoxynucleotides. Eur J Immunol 2006, 36:3238-3247.

64. Laabs EM, Wu W, Mendez S: Vaccination with live Leishmania major and CpG DNA promotes interleukin-2 production by dermal dendritic cells and NK cell activation. Clin Vaccine Immunol 2009, 16:1601-1606.

doi:10.1186/1471-2334-14-108

Cite this article as: Rodriguez-Pinto et al.: CD4 T cell activation by B cells in human Leishmania (Viannia) infection. BMC Infectious Diseases 2014 14:108.

\section{Submit your next manuscript to BioMed Central and take full advantage of:}

- Convenient online submission

- Thorough peer review

- No space constraints or color figure charges

- Immediate publication on acceptance

- Inclusion in PubMed, CAS, Scopus and Google Scholar

- Research which is freely available for redistribution 